\title{
Blood inorganic mercury is directly associated with glucose levels in the human population and may be linked to processed food intake
} \author{
Kingston $^{6}$, Mesay Mulugeta Wolle ${ }^{6}$, G.M. Mizanur Rahman ${ }^{6}$ and Dan R. Laks ${ }^{7}$ \\ ${ }^{1}$ Food Ingredient and Health Research Institute, Naalehu, Hawaii, USA \\ ${ }^{2}$ Fort Peck Community College, Poplar, Montana, USA \\ ${ }^{3}$ Shepherd University, Shepherdstown, West Virginia, USA \\ ${ }^{4}$ Department of Health and Nutrition Sciences, Brooklyn College of City University of New York, Brooklyn, New York, USA \\ ${ }^{5}$ Institute of Neurotoxicology and Neurological Disorders, Seattle, Washington, USA \\ ${ }^{6}$ Department of Chemistry and Biochemistry, Duquesne University, Pittsburgh, Pennsylvania, USA \\ ${ }^{7}$ Department of Biological Chemistry, University of California Los Angeles (UCLA), Los Angeles, California, USA
}

Renee Dufault ${ }^{* 1,2}$, Zara Berg ${ }^{2}$, Raquel Crider ${ }^{1,3}$, Roseanne Schnoll ${ }^{1,4}$, Larry Wetsit ${ }^{2}$, Wayne Two Bulls ${ }^{2}$, Steven G. Gilbert ${ }^{1,5}$, H.M. "Skip"

\begin{abstract}
Background: The goals of the study were (1) to determine the impact of inorganic mercury exposure on glucose homeostasis; and (2) to evaluate the effectiveness of two community-based interventions in promoting dietary changes among American Indian college students to reduce risk factors for Type-2 Diabetes including fasting glucose, insulin, and mercury levels, weight, and body mass index.

Methods: To accomplish goal one, the National Health and Nutrition Examination Survey (NHANES) dataset was analyzed using a previously published method to determine if there is a relationship between inorganic blood mercury and fasting glucose. To accomplish goal two, ten college students were recruited and randomly assigned to a group receiving the online macroepigenetics nutrition course and the support group for eliminating corn sweeteners. Participants in both groups were assessed for diet patterns, weight, body mass index (BMI), fasting glucose, insulin, and mercury levels. The interventions were implemented over a 10-week period.

Results: Analysis of the NHANES data $(n=16,232)$ determined a direct relationship between inorganic mercury in blood and fasting glucose levels ( $<<0.001)$. The participants who took the online macroepigenetics nutrition intervention course significantly improved their diets ( $p<0.01$ ), and fasting blood glucose levels ( $<<0.01$ ) while having lower levels of inorganic mercury in their blood compared to the subjects in the group who eliminated corn sweeteners from their diet and participated in the support group. The trend in lower blood inorganic mercury was strong with $\mathrm{p}=0.052$. The participants in the support group who eliminated corn sweeteners from their diet achieved significant weight loss $(\mathrm{p}<0.01)$ and reduced their body mass index $(\mathrm{p}<0.01)$.

Conclusion: Total blood mercury levels may be influenced by dietary intake of highly processed foods and lower inorganic mercury levels are associated with lower fasting glucose levels. Alternative community-based interventions emphasizing the role food ingredients and toxic substances play in gene modulation and the development of diseases can result in significant dietary improvements and reductions in risk factors associated with type- 2 diabetes. A healthier diet can be promoted among community members using a novel online nutrition course. Consumption of corn sweeteners may be a risk factor in the development of obesity.
\end{abstract}

\section{Background}

American Indians and Alaska Natives are persons having origins in any of the indigenous populations of North America who maintain tribal affiliation or membership [1]. Indian Country is comprised of American Indian (AI) and Alaska Native (AN) communities across the United States of America (USA). Compared with other Americans, AI and $\mathrm{AN}$ populations experience a disproportionate burden of chronic disease including liver disease and cirrhosis, diabetes, and heart disease $[2,3]$. Heart disease and type-2 diabetes (T2D) are the top two leading causes of death in AI and AN communities [2]. Diabetes prevalence rates are increasing among the $\mathrm{AI}$ and $\mathrm{AN}$ population aged 20 years or older and vary by region from $6.0 \%$ among AN adults to $24.1 \%$ among AI adults in southern Arizona [4,5]. Obesity is a significant risk factor in the development of both heart disease and T2D and contributes to the high prevalence rates of these diseases in Indian Country [6]. Although excess caloric consumption and a sedentary lifestyle are well known risk factors for obesity, T2D and heart disease, there is increasing evidence to suggest that exposure to toxic environmental substances and depletion of dietary micronutrients may play a significant role in the etiology of these diseases [7-10]. Toxic metal and pesticide exposures and excess consumption of food ingredients known to affect micronutrient status have been linked to the development of diabetes [8-11] through gene-environment interactions $[8,10,11]$.

Correspondence to: Renee Dufault, Food Ingredient and Health Research Institute, Naalehu, Hawaii, USA, E-mail: rdufault@foodingredient.info

Key words: macroepigenetics, fructose, corn syrup, diet, diabetes, online, glucose, NHANES, mercury

Received: April 10, 2015; Accepted: April 28, 2015; Published: May 02, 2015 
Adequate dietary intake of micronutrients is necessary to sustain metabolism and tissue function [12]. A recent study reported that concentrations of chromium $(\mathrm{Cr})$, copper $(\mathrm{Cu})$, manganese $(\mathrm{Mn})$, nickel $(\mathrm{Ni})$, lead $(\mathrm{Pb})$ and zinc $(\mathrm{Zn})$ in foodstuffs significantly correlated with that in human blood following intake [13]. In the only published report thus far about the dietary intake of a representative sample of the AI population, many of the AI men and women were not meeting the dietary recommendations for the key micronutrients magnesium $(\mathrm{Mg})$ and $\mathrm{Zn} \mathrm{[14].} \mathrm{This} \mathrm{finding} \mathrm{supports} \mathrm{the} \mathrm{conclusion} \mathrm{made} \mathrm{a} \mathrm{few} \mathrm{years}$ earlier by USA Department of Agriculture scientists who reported nearly one half of all Americans one year old and over had inadequate intakes of dietary $\mathrm{Mg}$ [15]. Such micronutrient insufficiencies over time may lead to increased risk for heart disease, diabetes, and neurodevelopmental disorders [16-19]. Zn, Mg, and phosphorus (P) losses can occur as a result of excess consumption of high fructose corn syrup (HFCS) and create imbalances in dietary micronutrient status $[20,21]$. Such imbalances are problematic from a macroscopic geneenvironment point of view since dietary micronutrient status can either exacerbate or mitigate the effects of exposure to toxic environmental substances by altering gene function especially in the case of child neurodevelopment and diabetes $[17,22,23]$. Fructose consumption in dietary conditions of magnesium deficiency induces insulin resistance while lowering PON1 gene activity [22,23]. PON1 gene expression is needed by the body to metabolize organophosphate pesticides known to adversely impact child neurodevelopment [17]. Child and reproductive health and diabetes are all health issues of grave concern to the indigenous populations of North America [24].

Health education can play a role in addressing these health issues if it is delivered in a culturally competent manner. Community based and culturally competent education efforts have made a positive difference in diabetes prevention efforts in minority communities by empowering community members to make lifestyle changes through the acquisition and dissemination of diabetes knowledge [25]. During the previous year, Fort Peck Community College (FPCC) collaborators developed and evaluated the efficacy of a culturally competent online nutrition intervention course [26]. The course was found to be effective in producing healthful dietary changes among community members who completed it [26].

The curriculum of the course is based on the underlying assumption that the prevalence of T2D among the AI population is due to the industrialization of the food supply, dietary exposure to toxic substances, and a general lack of knowledge among community members as to the epigenetic role food ingredients, nutrition, and invasive toxic substances play in the development of diseases. Epigenetic changes impacting human metabolism and health can occur through nutrition via dietary intake of methyl donating nutrients such as choline and betaine [27-29]. Macroepigenetics is a theoretical, consumer friendly approach that allows laypeople to consider how factors of nutrition, environment and gene expression interact to contribute to the development or prevention and inheritance of disease [17]. In accessing the macroepigenetics nutrition intervention course, participants are provided numerous opportunities to review research on the role nutritional factors and invasive toxic substances in the food supply play in gene modulation making them more susceptible to diabetes and other disease conditions. Participants learn that genes turn on and off in response to diet to produce the hormones and proteins needed by the body to regulate metabolism. They also learn that exposure to toxic substances such as mercury and fructose interfere with body metabolism. Participants finishing the online nutrition intervention course earn 3 units of science credit at FPCC. In this study, we wanted to determine if dietary changes resulting from participating in the online nutrition intervention course could result in reductions in risk factors associated with T2D including fasting blood glucose, insulin and mercury levels, weight, and body-mass-index (BMI).

Recognizing a one size fits all approach rarely works to resolve any health issue; we also wanted to offer an alternative intervention for individuals wishing to improve their health status by eliminating their consumption of corn sweeteners. Synthesized from corn starch [30] the targeted corn sweeteners included high fructose corn syrup (HFCS), corn syrup, modified corn starch, dextrose, maltodextrose, maltodextrin, and fructose. From a macroepigenetic perspective, HFCS is an invasive toxic substance for at least three different reasons. Its consumption by humans can result in dietary mercury exposure [31,32], and insulin resistance [33-35] and reduced PON1 gene activity in rats [22]. PON1 is the gene responsible for producing the paraoxonase enzyme required for breaking down the toxic organophosphate pesticide residues [22] found in wheat, corn, and wheat products [36]. Patients with T2D who have insulin resistance also have lower paraoxonase activity [37]. While it is unclear how decreased PON1 activity contributes to the development of $\mathrm{T} 2 \mathrm{D}$, there is evidence to suggest that inorganic mercury exposure plays a role in insulin resistance. Inorganic mercury exposure in the mercuric chloride $\left(\mathrm{HgCl}_{2}\right)$ form is suspected to be a contributing factor to the onset of insulin resistance by interfering with genes that regulate glucose homeostasis [38,39]. Exposure to inorganic mercury in the environment has also been found to contribute to the development of insulin resistance in non-diabetic humans by interacting with other toxins, such as dioxin $[28,40]$.

Mercury exposure can be determined through the analysis of a variety of tissues to include blood, urine, finger or toe nails, breast milk and hair [41]. Many studies have measured total $\mathrm{Hg}$ in blood without distinguishing the forms of mercury found in the blood [41]. This study was focused on determining the form of mercury exposure from consumption of processed foods. Inorganic mercury may enter food products during the various manufacturing processes. For example, mercury cell chlor-alkali chemical products are used extensively in food processing and always contain inorganic mercury residues. Vegetable oil products manufactured using the common alkali refining process may present a moderate risk of mercury contamination [42]. The mercury cell chlorine used to bleach flour is expected to contain a small amount of mercury residue [43]. The corn starch used to manufacture the corn sweeteners in the HFCS product line is treated purposely with inorganic $\mathrm{HgCl}_{2}$ as part of the manufacturing process to inhibit endogenous starch-degrading enzymes [30]. It is thus reasonable to suggest that consumers are routinely exposed to non-elemental inorganic mercury (I-Hg) when they consume heavily processed foods, including corn sweeteners. Our justification for adding the support group intervention to help students and community members eliminate corn sweeteners from their diet is based on the concept that consumption of corn sweeteners is both a known and potential source of inorganic mercury exposure $[31,32]$ and a potential factor in the development of insulin resistance [44].

\section{Methods}

The first goal of this study was to determine the impact of inorganic mercury exposure on glucose homeostasis through an analysis of the NHANES dataset. 


\section{NHANES dataset analysis}

The NHANES is a dataset of measured outcome variables such as biomarkers for the target population of the non-institutionalized, civilian United States population. The NHANES survey is generated in data groups of separate 2-year clusters. Our study analyzed the NHANES datasets combining survey clusters from 1999-2012 and was focused on the following biomarkers: fasting glucose, blood inorganic mercury (I-Hg), organic mercury, and insulin. In addition to analyzing blood I-Hg as a continuous variable, we also assessed its associations as a binary variable.

The rationale and methods to generate the binary variable blood I-Hg detection (I-Hg detect) are detailed in Laks [45]. We set a constant value across survey years for the limit of detection (LOD) based on the first survey years limit of detection $(0.4 \mathrm{ug} / \mathrm{L})$ and used that as a standardized baseline. Thereby, we generated a binary variable for $\mathrm{I}-\mathrm{Hg}$ detection, where $0=$ no detection (below $0.4 \mathrm{ug} / \mathrm{L}$ ) and $1=$ positive detection (above or equal to $0.4 \mathrm{ug} / \mathrm{L}$ ). This maintained a standardized limit of detection for all survey groups. This coding procedure was followed because most values for blood I-Hg fell below the LOD and were assigned estimate values that changed across survey years. Thus, LBXIHG, the NHANES variable for I-Hg is not an optimal continuous variable but may be better assessed as a binary variable of detection/no detection. To compensate for the changing estimate values below the LOD, values below our assigned and uniform LOD of $0.4 \mathrm{ug} / \mathrm{L}$ were assigned a constant estimate value of $0.3 \mathrm{ug} / \mathrm{L}$ which was the estimate value used for the initial 1999-2000 survey set. We stress that this was done only to estimate the rate of $\mathrm{I}-\mathrm{Hg}$ detection in blood. In order to determine associations with blood I-Hg concentration we also used the primary NHANES continuous variable, LBXIHG (blood I-Hg). We found comparable results for associations with both $\mathrm{I}-\mathrm{Hg}$ detection and $\mathrm{I}-\mathrm{Hg}$ mean concentration. In addition, we generated a value for blood organic mercury, $\mathrm{CH}_{3} \mathrm{Hg}$ by subtracting blood I-Hg (LBXIHG) from total blood mercury (LBXTHG).

This study analyzed both the raw population and the survey weighted population in order to detect robust associations. The survey-weighted population extends the inferences based on our findings to the U.S. population and utilizes a weighting adjustment as outlined in the NHANES website. The stratum and PSU variables assist in estimating variances in order to reflect the design structure of the NHANES survey. In STATA the 1999-2012 NHANES combined data set is weighted for survey analysis by: svyset(pw=WT99-2012), psu(sdmvpsu), strata(sdmvstra) where WT99-2012 is the combined weight calculated above. We chose to report as significant only those associations with p-values less than 0.01 in the survey-weighted population.

The NHANES population analyzed was the full NHANES population available with measured blood I-Hg levels. However, we also adjusted for potential confounders and used multivariate analysis to adjust for age, race and gender. We used linear regression and logistic regression models when appropriate. Statistical analysis of the NHANES dataset was performed using STATA 8.0 (StatCorp).

\section{Health education interventions}

The second goal of this study was to evaluate the effectiveness of two health education interventions in reducing risk factors for T2D: the online macroepigenetics nutrition course (MAC) and the support group for corn sweetener elimination (CSE). Participants in both groups were assessed for weight, BMI, fasting glucose, insulin, and mercury levels. The interventions were implemented over a 10-week period.

This study was conducted at the Fort Peck Community College (FPCC) in compliance with a protocol approved by a third party non-profit Institutional Review Board (IRB), the BioMed IRB [46]. The tribe did not have their own IRB at the time but the Fort Peck Tribal Executive Board passed a resolution in support of the members participating in a macroepigenetic study of changes in health status following the nutrition education intervention program at FPCC. Located in Popular, Montana on the Fort Peck Indian Reservation, FPCC is a tribally controlled community college chartered by the government of the Fort Peck Assiniboine and Sioux Tribes. The macroepigenetics nutrition intervention course (MAC) and pretest and posttest food frequency survey questionnaire were delivered on line via the non-profit Food Ingredient and Health Research Institute (FIHRI) website [47] to the FPCC students. The corn sweetener elimination (CSE) support group intervention was delivered by FPCC teaching staff. While ten community members initially enrolled in the study only nine successfully participated in one of the alternative interventions offered during the study.

The nursing staff at the Northeast Montana Health Services (NEMHS) Riverside Clinic screened ten participants and randomly assigned half of them to the CSE intervention group. The five participants in the CSE group were asked to eliminate corn sweeteners in the HFCS product line from their diet and participate in a support group. Screening was conducted to ensure that participants, regardless of the intervention assigned, were at least 20 years of age and not on any medication except birth control. The nursing staff was also responsible for collecting weight and height measurements, and blood samples for biomarker analysis.

Community members participating in either the online intervention course (MAC) or the CSE group received a monthly stipend of $\$ 200$ for each month of successful participation. Success in the nutrition intervention course (MAC) was determined by completed homework submissions, participation in the online peer group discussion forum, and completion of a culminating final project. Success in the support group (CSE) was determined by meeting weekly with the support group coordinator. The stipend was provided to compensate the community members for their time in completing the online course work with the embedded pre and post food frequency survey or meeting weekly with the support group coordinator, and providing blood samples for analysis and height and weight measurements for determining BMI.

\section{MAC intervention course}

The online MAC course consisted of ten modules of culturally competent instruction delivered over ten weeks at the FIHRI website which also provides an outline of the course content [47]. Each of the five participants in the course was provided with their own unique password to access the modules of instruction. The curriculum provided opportunities for independent research, collaboration, and peer group interactions to discuss lessons learned. For example, during the third module of instruction, participants were required to access the United States Department of Agriculture (USDA) Food Availability Data System and determine the average per capita availability and consumption for various foods consumed in the US [48]. After compiling their data, they were then asked to interpret the changes in commodity consumption over time and how these changes might contribute to the development of modern diseases. Table 1 provides an example of the data the participants gathered for sugars and vegetable 
Table 1. Change in American sugar and vegetable oil consumption 1970-2010.

\begin{tabular}{|c|c|c|c|}
\hline Commodity & 1970 per capita consumption (Lbs/year) & 2010 per capita consumption (Lbs/year) & Percent increase or decrease \\
\hline Cane and beet sugar & 59.8 & 38.7 & $-35 \%$ \\
\hline High fructose corn syrup & 0.3 & 28.7 & $+9,467 \%$ \\
\hline Total corn sweeteners, including high fructose corn syrup & 9.3 & 37.8 & $+306 \%$ \\
\hline Vegetable oils (salad and cooking) & 15.4 & 53.6 & $+248 \%$ \\
\hline
\end{tabular}

oils from 1970 to 2010. The participants were able to compare the per capita American consumption rates of high fructose corn syrup, cane and beet sugar, total corn sweeteners, and vegetable oils over time. Using the USDA data, the participants determined that from 1970 to 2010, cane and beet sugar consumption decreased 35\% while high fructose corn syrup consumption increased $9,467 \%$. During the same period of time, per capita vegetable oil consumption increased $248 \%$. In their online forum, they discussed the potential impact of this increased high fructose corn syrup and vegetable oil consumption on Indian health. In a later module, the participants reviewed peer reviewed journal articles and learned that fructose consumption impacts PON1 gene activity which may create conditions of oxidative stress leading to the development of insulin resistance and T2D [22].

To evaluate whether or not the curriculum was effective in reducing participant consumption of food commodities and ingredients that lead to the development of chronic diseases, a one-group pretestposttest survey was designed and administered online prior to and after receiving the instruction over the 10-week long intervention period. The IRB approved survey was constructed and delivered using the online Survey Monkey tool [49]. Food frequency questions were modeled after those used by the National Cancer Institute [50] to query dietary intake during the past month. Using the same format we developed three additional questions to determine the intake of organic flour, organic vegetables and fruit, and organic processed foods (crackers, bread, and cereal).

\section{CSE support group intervention}

Participants in the CSE support group were provided the following:

- A shopping guide with food ingredients to avoid including HFCS, corn syrup, modified corn starch, dextrose, maltodextrose, maltodextrin, and fructose.

- Instructions on the importance of reading food ingredient labels as opposed to "nutrition facts."

- Field trip to grocery store with one-on-one support instruction on reading food ingredient labels.

- $\quad$ Alternative recipes for preparing favorite meals without corn sweetener ingredients. For example, corn syrup was eliminated as an ingredient in making Indian fry bread.

\section{Participant blood sample analyses}

Pre- and post-intervention blood samples were analyzed successfully to determine fasting glucose and insulin levels using standard methods at the local clinical laboratory. Insulin and glucose measurements for each participant were entered into the Hepatitis C Society's online homeostasis model of assessment for insulin resistance (HOMA-IR) calculator [51] for determining the degree of insulin resistance.

The pre-intervention blood testing was performed at the Mayo clinic but because measurements were reported as $<1,1$ or $>1 \mathrm{xg} / \mathrm{g}$ mercury $(\mathrm{Hg})$, they were not useful for our purpose which was to measure lower detectable $\mathrm{Hg}$ exposures. Post-intervention $\mathrm{Hg}$ samples were sent to Duquesne University for analysis using a method developed for and used by the Centers for Disease Control and Prevention (CDC) [52]. These samples were analyzed for total $\mathrm{Hg}$ based on microwave enhanced sample digestion (EPA Method 3052) with direct isotope dilution mass spectrometry, D-IDMS (EPA Method 6800) using Agilent 7700 inductively coupled plasma mass spectrometry (ICP-MS). In addition, two of the post intervention blood samples were analyzed for $\mathrm{Hg}^{2+}$ and $\mathrm{CH}_{3} \mathrm{Hg}^{+}$based on microwave enhanced extraction (EPA Method 3200) with speciated isotope dilution mass spectrometry, SIDMS (EPA Method 6800) using Agilent 7890 gas chromatograph (GC) connected to Agilent 7700 ICP-MS. The method was capable of detecting $\mathrm{Hg}$ species down to ng/g levels. Each of these EPA numbered methods were developed by the same research laboratory at Duquesne University and validated and published by the Environmental Protection Agency (EPA) under Resource Conservation and Recovery Act (RCRA) statues [53].

\section{Statistical analysis of pilot study data}

Statistical analysis was performed using Excel software. Results are expressed as mean difference and standard deviation (SD). A p value of $<0.01$ is considered significant. A one tailed t-test analysis was conducted to compare the mean of the difference pre and post within each intervention group. In the comparison of the post intervention mercury levels, the online SISA analytical tool [54] was used to conduct the $\mathrm{t}$-test of the means for the two unequal samples $(\mathrm{n}=5$ and $n=4$ ). The diet score data in Table 2 was tallied using a scoring method of providing one point for each item if the participant in the MAC intervention course reported a diet habit consistent with the instruction. For example, in scoring each question on highly processed food consumption, participants reporting less consumption were awarded one point. The higher score in this category indicates less consumption of highly processed foods. Conversely, the higher score in the whole foods (minimal processing) and/or organic products category indicates more consumption of foods less likely to contain invasive toxic substances introduced through processing.

\section{Results of NHANES dataset analyses}

In the NHANES 1999-2012 dataset, $n=16,232$, we found a significant, direct relationship between blood inorganic mercury (I$\mathrm{Hg}$ ) and fasting blood glucose (Table 3). This was true of both the continuous variable for blood inorganic mercury (I-Hg concentration, $\mathrm{p}<0.001)$ and the binary variable, $\mathrm{I}-\mathrm{Hg} \operatorname{detect}(\mathrm{OR} 1.03, \mathrm{p}=0.006)$. After adjustment for age, race, and gender, $\mathrm{I}-\mathrm{Hg}$ concentration remains significantly associated $(\mathrm{p}<0.001)$ with blood glucose levels in the survey-weighted population. Figure 1 shows these associations that were significant in the raw and survey weighted populations and after adjusting for age, race, and gender. Although blood organic mercury was associated with glucose levels $(\mathrm{p}<0.001)$, this correlation fell out and became not significant when adjusted for age, race and gender $(\mathrm{p}=0.097)$. However, blood organic mercury was inversely associated with insulin levels even after adjusting for age, race, and gender $(\mathrm{p}<0.001)$. Our results indicate that blood glucose and inorganic 
Dufault R (2015) Blood inorganic mercury is directly associated with glucose levels in the human population and may be linked to processed food intake

Table 2. Food frequency survey diet scores for MAC participants.

\section{Category}

Questions

Corn sweeteners, refined or high sugar

How often do you drink a sugar sweetened beverage (do not include diet drinks)? ${ }^{\text {a }}$

How often do you drink an energy drink? ${ }^{\text {a }}$

During the past month, how many times did you eat canned fruit (applesauce, apricot halves, mixed fruit, pears, cling peaches)? a

During the past month, how many times did you drink $100 \%$ fruit juice (apple, orange, grape, cranberry, other)? ${ }^{\mathrm{c}}$

During the past month, how many times did you eat "sweet snacks" such as candy, cookies, ice cream, popsicle, other sugar

sweetened treat (do not include diet)? ${ }^{\mathrm{d}}$

Total score for category

Mean

SD

\section{Fish}

How many times in the past month have you eaten freshly caught fish? ${ }^{\mathrm{b}}$

During the past month, how many times did you eat canned tuna? ${ }^{\mathrm{b}}$

During the past month, how many times did you eat canned salmon? ${ }^{\mathrm{c}}$

Total score for category

Mean

SD

Whole foods (minimal processing) and/or organic products

During the past month, how many times did you eat fresh or frozen fruit (bananas, oranges, apples, strawberries, etc....)? ${ }^{\mathrm{e}}$

During the past month, how many times did you eat fresh vegetables (spinach, lettuce, tomato, carrot, green salad, etc...)?

Whole foods (minimal processing) and/or organic products

During the past month, how many times did you eat frozen vegetables (corn, broccoli, peas, green beans, etc....)? ${ }^{\mathrm{e}}$

During the past month, how many times did you eat poultry (chicken or turkey)? ${ }^{\mathrm{e}}$

How often in the past month, did you eat red meat (hamburger, pork, ham, or sausage) ${ }^{\mathrm{d}}{ }^{\text {(moderation) }}$

During the past month, how many times did you eat "brown rice"? ${ }^{\mathrm{f}}$

During the past month, how many times did you eat oats (oat meal)? ${ }^{\mathrm{f}}$

During the past month, how many times did you eat canned vegetables (green beans, carrots, corn, peas, spinach, sweet potatoes, diced tomato, mixed vegetables)? ${ }^{\mathrm{b}}$ (moderation)

How many times in the past month did you eat foods prepared with organic flour? ${ }^{\mathrm{f}}$

How many times in the last month did you eat organic vegetables or fruit (fresh or frozen)? ${ }^{f}$

How many times in the past month did you eat organic processed foods (crackers, bread, cereal, canned vegetables, salad dressing, etc....) ${ }^{\mathrm{f}}$

Total score for category

Mean

SD

\section{Highly processed foods}

During the past month, how many times did you eat canned meals (soup, re-fried beans, chili with and without beans, beef stew, etc..) ${ }^{\mathrm{d}}$

During the past month, how many times did you eat processed cheese (American)? ${ }^{\text {a }}$

During the past month, how many times did you eat processed meat (lunch meat, hotdogs, bacon, beef jerky, etc...)? ${ }^{\mathrm{d}}$

During the past month, how many times did you eat ready-to-eat cereal (corn flakes, rice crisp, corn squares, oat circles, etc....)? ${ }^{\mathrm{d}}$

During the past month, how many times did you eat foods fried in vegetable oil, lard, or butter, such as potato chips, french fries, fry bread, doughnuts, hash browns, fried eggs, etc...? ${ }^{\mathrm{d}}$

During the past month, how many times did you eat "salty" snacks such as potato chips, pretzels, corn chips, pop-corn, etc...? ${ }^{\mathrm{d}}$

During the past month, how many times did you eat grain products made of wheat such as macaroni, bread, hamburger buns, hotdog buns, or spaghetti? ${ }^{\mathrm{d}}$

During the past month, how many times did you eat "white" rice? ${ }^{\mathrm{d}}$

During the past month, how many times did you eat meals prepared in restaurants, fast food places, pizza parlors, or from vending machines? $^{\mathrm{d}}$

Total score for category

Mean

SD ${ }^{a}$ score $=1$ if "never, rarely (once or twice a month)" ${ }^{\mathrm{b}}$ score $=1$ if "once a week, rarely (once or twice a month)" "score $=1$ if "once a week, several times a week, every day (1-2 servings)"
${ }^{\mathrm{d}}$ score $=1$ if "never, rarely, once a week" " score $=1$ if "several times a week, pretty much every day (1-2 servings), several times a day ( 3 or more servings)" score $=1$ if "rarely (once or twice a month), once a week, several times a week, pretty much every day (1-2 servings)"

mercury ( $\mathrm{I}-\mathrm{Hg}$ ) share an association that is unique to this mercury speciation. The inverse association between blood organic mercury with insulin suggests a complex relationship between the levels of different mercury forms, glucose and insulin.

\section{Results of Health Education Interventions}

All ten participants received instruction on the macroepigenetic model for insulin resistance by attending the pre-intervention workshop 
Table 3. Mercury $(\mathrm{Hg})$ as a function of glucose (mM) in NHANES 1999-2012 Survey Weighted Population.

\begin{tabular}{|c|c|c|c|c|c|c|}
\hline Population & Hg Species & Outcome & Regression & Correlation & Confidence & P-value \\
\hline $\mathrm{N}=16,232, \mathrm{SP}=4.137 \mathrm{e}+08$ & Blood I-Hga & Glucose (mM) & Linear & $\beta=0.00260$ & CI (0.00234-0.00286) & $\mathrm{p}<0.001$ \\
\hline \multirow[t]{3}{*}{$\mathrm{N}=16,232, \mathrm{SP}=4.137 \mathrm{e}+08 \mathrm{Adj}$. for age, gender, race } & \multirow[t]{3}{*}{ Blood I- $\mathrm{Hg}^{\mathrm{a}}$} & Glucose (mM) & Linear & $\beta=0.00150$ & CI (0.00123-0.00178) & $\mathrm{p}<0.001$ \\
\hline & & MA (vs CAU) & Linear & $\beta=0.00184$ & CI (0.00078-0.00289) & $\mathrm{p}=0.001$ \\
\hline & & Black (vs CAU) & Linear & $\beta=0.00394$ & CI $(0.00312-0.00475)$ & $\mathrm{p}<0.001$ \\
\hline $\mathrm{N}=16,232, \mathrm{SP}=4.137 \mathrm{e}+08$ & Blood I-Hg ${ }^{\mathrm{b}}$ & Glucose (mM) & Logistic & $\mathrm{OR}=1.03395$ & CI (1.00980-1.05867) & $\mathrm{p}=0.006$ \\
\hline \multirow{2}{*}{$\begin{array}{l}\mathrm{N}=16,232, \mathrm{SP}=4.137 \mathrm{e}+08 \\
\text { Adj. for race and gender }\end{array}$} & \multirow[t]{2}{*}{ Blood I-Hg } & Glucose (mM) & Logistic & $\mathrm{OR}=1.04260$ & CI (1.01674-1.06911) & $\mathrm{p}=0.001$ \\
\hline & & MA (vs CAU) & Logistic & $\mathrm{OR}=0.70323$ & CI (0.58613-0.84372) & $\mathrm{p}<0.001$ \\
\hline $\mathrm{N}=16,230, \mathrm{SP}=4.137 \mathrm{e}+08$ & Blood Organic $\mathrm{Hg}^{\mathrm{a}}$ & Glucose (mM) & Linear & $\beta=0.05923$ & CI (0.03654- 0.08193) & $\mathrm{p}<0.001$ \\
\hline $\mathrm{N}=16,230, \mathrm{SP}=4.137 \mathrm{e}+08$ Adj. for age, gender, race & Blood Organic $\mathrm{Hg}^{\mathrm{a}}$ & Glucose (mM) & Linear & $\beta=0.01952$ & CI (-0.00364- 0.04268) & $\mathrm{p}=0.097$ \\
\hline $\mathrm{N}=16,230, \mathrm{SP}=4.137 \mathrm{e}+08$ & Blood Organic $\mathrm{Hg}^{\mathrm{a}}$ & Insulin (pM) & Linear & $\beta=-0.00121$ & CI (-0.00165- -0.00076) & $\mathrm{p}<0.001$ \\
\hline $\mathrm{N}=16,230, \mathrm{SP}=4.137 \mathrm{e}+08 \mathrm{Adj}$. for age, gender, race & Blood Organic $\mathrm{Hg}^{\mathrm{a}}$ & Insulin (pM) & Linear & $\beta=-0.00120$ & CI (-0.00161- -0.00078) & $\mathrm{p}<0.001$ \\
\hline
\end{tabular}

$\mathrm{N}=$ Raw Population, $\mathrm{SP}=$ Survey Population, $\mathrm{Adj}=$ adjusted, $\mathrm{I}-\mathrm{Hg}=$ Inorganic Mercury, ug $/ \mathrm{L}=$ micrograms $/$ liter, $\mathrm{mM}=$ millimolar, $\beta=$ coefficient, ${ }^{a}$ refers to concentration of mercury(ug/L), ${ }^{\mathrm{b}}$ refers to detection above $0.4 \mathrm{ug} / \mathrm{L}$ blood $\mathrm{I}-\mathrm{Hg}, \mathrm{CI}=$ Confidence Interval, $\mathrm{MA}=$ Mexican American, $\mathrm{CAU}=\mathrm{Caucasian}, \mathrm{OR}=\mathrm{Odds}$ Ratio, $\mathrm{pM}=$ picomolar

\section{A 1999-2012 NHANES- Raw Population}
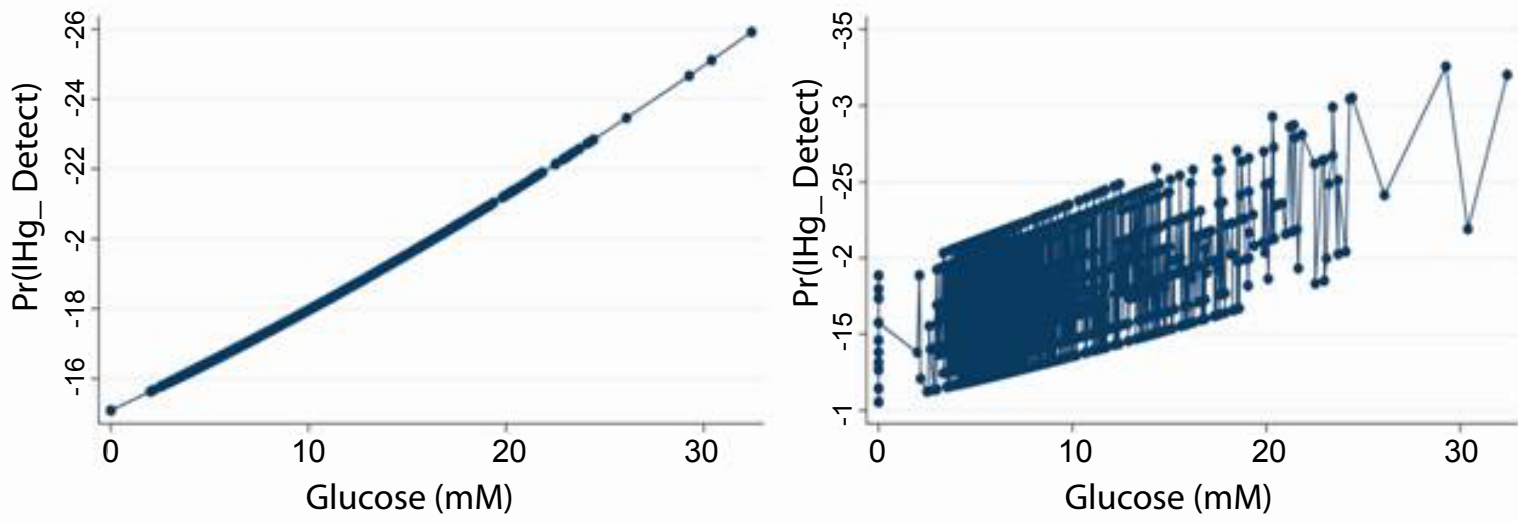

C
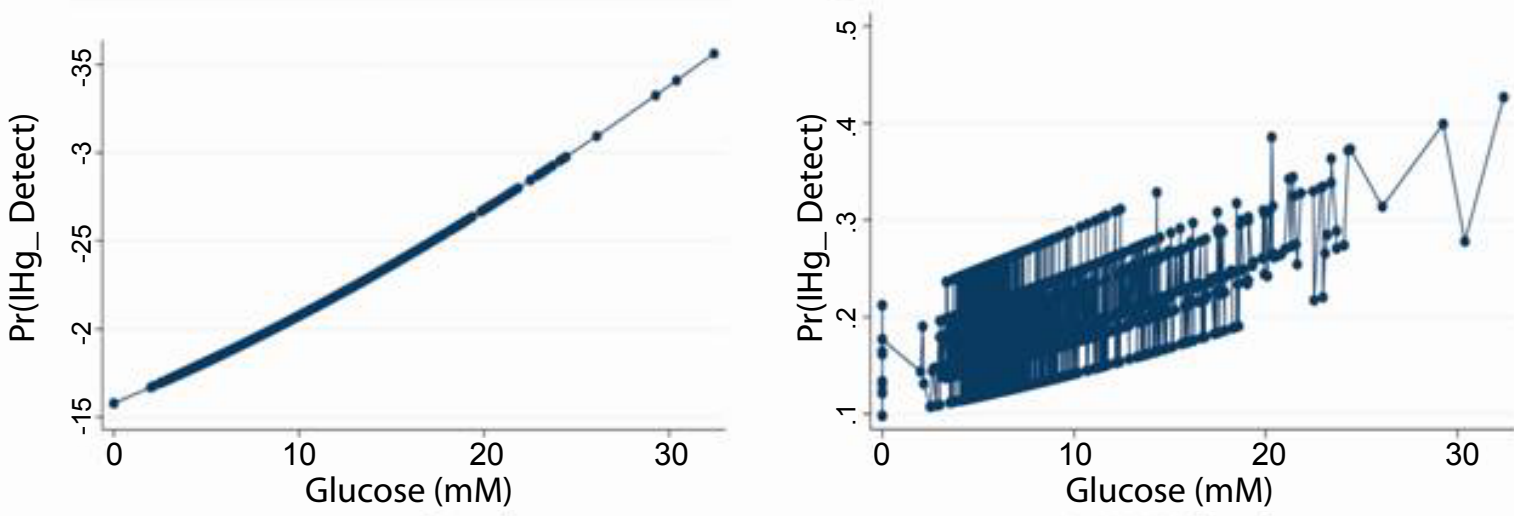

$\mathrm{I}-\mathrm{Hg}$ Detection $=$ above $0.4 \mathrm{ug} / \mathrm{L}$

Figure 1: Inorganic $\mathrm{Hg}(\mathrm{I}-\mathrm{Hg})$ detection is directly associated with fasting glucose in the NHANES 1999-2012 dataset.

Legend: A. Display of logistic regression illustrates that the probability of I-Hg detection in blood (above $0.4 \mathrm{ug} / \mathrm{L}$ ) is directly associated with fasting glucose levels in the raw NHANES population (Odds Ratio 1.02114, $\mathrm{p}=0.034, \mathrm{~N}=16,232$ ). B. Same as A except this is a multivariate analysis that adjusts for race and sex (Odds Ratio 1.02886 , $\mathrm{p}=0.004$, $\mathrm{N}=16,232$ ). C. Same as A except this is the survey weighted population (Odds Ratio 1.03395, $\mathrm{p}=0.006, \mathrm{~N}=16,232, \mathrm{SP}=4.137 \mathrm{e}+08$ ). D. Same as B except this is a survey weighted population (Odds Ratio 1.04260 , $\mathrm{p}=0.001, \mathrm{~N}=16,232, \mathrm{SP}=4.137 \mathrm{e}+08)$. 
or participating in the online course. Of the ten participants in the study, five who were not assigned to the CSE group successfully completed the online intervention course (MAC). Four of the five participants in the CSE group successfully eliminated corn sweeteners from their diet. There was one drop out in the CSE group. Blood samples were collected from all ten participants pre and post intervention(s) and analyzed for mercury as well as glucose and insulin to determine insulin resistance using the homeostasis model of assessment for insulin resistance (HOMA-IR). The data from the CSE group drop out was omitted and not included in the analysis of the results. In post-intervention interviews, this participant admitted she was unable to comply with the protocol and abstain from corn sweetener consumption.

\section{MAC intervention course}

Pre-test blood samples were collected for analysis from the five intervention course participants the third week of January 2013 and post-test blood samples were collected for analysis the first week of April 2013. Matched data on dietary intake were also collected from the intervention course participants who completed the IRB approved food frequency survey questionnaire online at two points in time during the online macroepigenetics nutrition intervention course. The first pre-test survey was administered during the third week of January 2013. The second post-test survey was completed by the participants in the same manner at the end of the 10-week course.

The diet behavior score data derived from the embedded food frequency survey administered during the online macroepigenetics nutrition intervention course are provided in Table 2. An item was scored positively if the subject reported a diet habit consistent with the instruction. Higher scores indicate a healthier diet. The data show a significant difference between the pre and post periods in the category of questions used to measure participant consumption of whole foods with minimal processing and/or organic food products. The total preintervention diet score is 27 and the post- intervention diet score is 42 . The t-test analysis was significant with $\mathrm{p}<0.01$. These findings indicate the participants significantly increased their consumption of whole foods with minimal processing and/or organic food products. There was no change in the participants' fish consumption, however, between the pre and post periods. In the category of questions used to measure fish consumption, the total pre-intervention diet score is 5 and the post intervention score is 6 . The $t$-test analysis was not significant with $\mathrm{p}>0.05$.

The diet score data in Table 2 also show a significant difference between the pre and post periods in the category of questions used to measure participant consumption of highly processed foods, excluding

Table 4. Changes in health status observed in macroepigenetics nutrition intervention course (MAC) group.

\begin{tabular}{|l|c|c|c|}
\hline $\begin{array}{l}\text { Online macroepigenetics nutrition } \\
\text { intervention course (MAC) Group }\end{array}$ & $\begin{array}{c}\text { Pre } \\
\mathbf{n = 5}\end{array}$ & $\begin{array}{c}\text { Post } \\
\mathbf{n = 5}\end{array}$ & p-value \\
\hline Mean weight (in pounds) & 194.24 & 189.88 & \\
SD & 59.90 & 55.31 & \\
\hline Mean BMI & 29.44 & 28.8 & \\
SD & 5.76 & 5.17 & \\
\hline Mean fasting glucose (mg/dL) & 101.4 & 88 & $<\mathbf{0 . 0 1}$ \\
SD & 8.14 & 8.40 & \\
\hline Mean insulin (uU/ml) & 15.9 & 13.82 & \\
SD & 13.32 & 11.46 & \\
\hline Mean HOMA-IR & 4.14 & $2.98^{\mathrm{a}}$ & \\
SD & 3.64 & 2.40 & \\
\hline
\end{tabular}

BMI $=$ Body Mass Index, $\mathrm{SD}=$ Standard Deviation, HOMA-IR $=$ Homeostasis Model of Assessment for Insulin Resistance, ${ }^{a}$ Lower HOMA-IR values significantly reduce risk for cardiovascular disease event [95].
Table 5. Changes in health status observed in corn sweetener elimination (CSE) group.

\begin{tabular}{|l|c|c|c|}
\hline Corn sweetener elimination (CSE) group & $\begin{array}{c}\text { Pre } \\
\mathbf{n = 4}\end{array}$ & $\begin{array}{c}\text { Post } \\
\mathbf{n = 4}\end{array}$ & p-value \\
\hline Mean weight (in pounds) & 216.3 & 209.3 & $<\mathbf{0 . 0 1}$ \\
SD & 60.03 & 60.22 & \\
\hline Mean BMI & 33.45 & 32.35 & $<\mathbf{0 . 0 1}$ \\
SD & 8.27 & 8.29 & \\
\hline Mean fasting glucose (mg/dL) & 97.75 & 82 & \\
SD & 11.62 & 11.40 & \\
\hline Mean insulin (uU/ml) & 11.98 & 12.58 & \\
SD & 4.89 & 7.31 & \\
\hline Mean HOMA-IR & 2.92 & 2.76 & \\
SD & 1.34 & 1.77 & \\
\hline
\end{tabular}

BMI = Body Mass Index, $\mathrm{SD}=$ Standard Deviation, HOMA-IR $=$ Homeostasis Model of Assessment for Insulin Resistance

corn sweeteners and sugars. For the highly processed food category, the total pre-intervention diet score was 27 and the post-intervention diet score was 38 . The $t$-test analysis was significant with $\mathrm{p}<0.01$. The increase in this diet score indicates participants significantly reduced their consumption of highly processed foods. Participants also reduced their intake of foods comprised of corn sweeteners or high in sugar but there was not a significant difference in the pre and post-intervention diet scores for this category of questions. The total pre-intervention diet score is 13 and the post intervention score is 18 . The $t$-test analysis was not significant with $\mathrm{p}>0.05$. The increased score in this category, however, indicates the participants reduced their overall corn sweetener and sugar intake.

Table 4 shows a significant difference between the average fasting blood glucose measurements in the two periods. The average fasting blood glucose for the 5 matched subjects is $101.4 \mathrm{mg} / \mathrm{dL}$ in the pre- test period and $88 \mathrm{mg} / \mathrm{dLin}$ the post- test period at the end of the 10 week intervention period. The t-test analysis was significant with $\mathrm{p}<0.01$. The analysis of the plasma insulin data show there is no significant difference between the pre and post test although there is a downward trend in the average insulin between the two time periods. The average fasting insulin for the 5 matched participants is $15.9 \mathrm{uU} / \mathrm{ml}$ in the pre test and $13.82 \mathrm{uU} / \mathrm{ml}$ in the post-test. The analysis of the HOMA-IR data show there is no significant difference between the pre and post test although there is a downward trend in the average HOMA-IR between the two periods. The average HOMA-IR for the 5 matched participants is 4.14 in the pre test and 2.98 in the post-test.

Table 4 also shows the analyses of the BMI and weight data. For both indices there is no significant difference between the averages in the two periods. Average BMI for the 5 matched participants is 29.44 in the pre test, and 28.8 in the post-test. The t-test analysis was not significant. The weight data show no significant difference between the pre and post test although there is a downward trend in the average weight between the two time periods. The average weight for the 5 matched participants is 194.24 pounds in the pre-test and 189.88 pounds in the post-test.

\section{CSE support group intervention}

Matched data pre and post for the blood sample analyses were collected from all four participants in the CSE group who gave blood samples at two points in time during the 10-week support group intervention for the elimination of corn sweeteners. The first pre-test samples were collected before the first support group meeting during the third week of January 2013. The second post-test samples were collected the first week of April 2013 at the end of the intervention 
Table 6. Difference in mercury $(\mathrm{Hg})$ levels post intervention.

\begin{tabular}{|l|c|c|c|}
\hline Intervention group & $\begin{array}{c}\text { Mean total post } \\
\text { mercury (Hg) level } \\
\text { (ng/g) }\end{array}$ & SD & p-value \\
\hline $\begin{array}{l}\text { Corn sweetener elimination group } \\
\text { (CSE, } \mathrm{n}=4)\end{array}$ & 1.325 & 0.849 & 0.052 \\
\hline $\begin{array}{l}\text { Online macroepigenetics nutrition } \\
\text { intervention course (MAC, } \mathrm{n}=5)\end{array}$ & 0.332 & 0.100 & \\
\hline
\end{tabular}

period.

Table 5 shows that there is significant difference between the average weight and BMI measurements in the two periods. The average weight for the 4 matched participants is 216.3 pounds in the pre-test period and 209.3 pounds in the post-test period. The t-test analysis was significant with $\mathrm{p}<0.01$. The average BMI for the 4 matched participants is 33.45 in the pre-test period and 32.35 in the post- test period. The t-test analysis was significant with $\mathrm{p}<0.01$. The participants who eliminated corn sweeteners from their diet showed significant losses in both weight and BMI.

Table 5 also provides the fasting glucose data that show no significant difference between the pre and post test although there is a downward trend in the average fasting glucose between the two time periods. The average fasting blood glucose for the 4 matched subjects is $97.75 \mathrm{mg} / \mathrm{dL}$ in the pre test period and $82 \mathrm{mg} / \mathrm{dL}$ in the post test period at the end of the 10 week intervention period. The t-test analysis was not significant. The analysis of the plasma insulin data show there is no significant difference between the pre and post test. The average fasting insulin for the 4 matched participants is $11.98 \mathrm{uU} / \mathrm{ml}$ in the pre test and $12.58 \mathrm{uU} / \mathrm{ml}$ in the post-test. The analysis of the HOMA-IR data show there is no significant difference between the pre and post test although there is a slight downward trend in the average HOMA-IR between the two periods. The average HOMA-IR for the 4 matched participants is 2.92 in the pre test and 2.76 in the post-test.

\section{Post intervention mercury $(\mathrm{Hg})$ results}

Post intervention $\mathrm{Hg}$ levels of the participants in the two intervention groups were analyzed and compared and the results are provided in Table 6 . The blood samples were analyzed for total $\mathrm{Hg}$, inorganic mercury (I-Hg) and methyl mercury. The mercury species found in the blood samples were exclusively inorganic mercury (I$\mathrm{Hg}$ ), and no methlymercury was detected in any of the blood samples analyzed at the sub-ng/g detection limit levels. The average total Hg level for the CSE group is $1.325 \mathrm{ng} / \mathrm{g}$ and the average total $\mathrm{Hg}$ level for the online MAC intervention course group is $0.332 \mathrm{ng} / \mathrm{g}$. Although there is a large difference in the average $\mathrm{Hg}$ levels between the two groups, the difference is not significant with $p=0.052$. The difference in the post $\mathrm{Hg}$ levels between the two intervention groups and the reductions in fasting glucose levels observed in both intervention groups suggested inorganic $\mathrm{Hg}$ may play a role in glucose homeostasis.

\section{Discussion}

Dietary behavior plays a significant role in determining risk of T2D and other chronic diseases in the AI population. Consumption of specific food ingredients can lead to obesity and increased risk of T2D. Goran, Ulijaszek and Ventura [55] found that diabetes prevalence was $20 \%$ higher in countries with higher availability of high fructose corn syrup (HFCS). Corn sweeteners, including HFCS have been pervasive as an ingredient available in the AI food supply since the 1970's and may be a source of mercury exposure [31,32]. The Pima, an AI tribe in southern Arizona, have the highest prevalence of T2D in the world, yet their genetically related indigenous counterpart, living across the American border in Mexico; have at least 5 times less diabetes [56]. Esparza-Romero et al. [56] found that Mexican Pima with normal glucose levels have lower mean insulin resistance (HOMA-IR 1.40) compared to their AI counterpart (HOMA-IR 3.07), even after controlling for differences in obesity, age, and sex. The difference in HOMA-IR between groups could only be partially explained by the greater degree of obesity in the AI Pima [56]. One explanation for the greater obesity in the AI Pima could be their exposure to HFCS. HFCS was not available for consumption in Mexico during and many years prior to the study period [57]. Up until 2008, Mexico severely limited imports of HFCS to protect their sugar market [57].

HFCS consumption is thought to play a role in the obesity epidemic but the genetic mechanisms remain unclear [58]. Stanhope et al. [59] compared metabolic outcomes for two different groups of human subjects, one fed fructose sweetened beverages $(n=17)$ and the other fed glucose sweetened beverages $(n=15)$ for eight weeks. The fructose fed group significantly increased their belly fat compared to the glucose fed group and exhibited greater insulin resistance [59]. Fasting glucose levels also increased in the subjects fed fructose [59].

In the present study, the participants in the CSE group significantly reduced their weight and BMI with the elimination of fructose and other corn sweeteners from their diets. All had normal fasting glucose levels at the beginning of the study that decreased over the 10 -week intervention period. A downward trend in the HOMA-IR value was also observed suggesting that with the loss in weight and BMI, the participants significantly reduced their risk of T2D. The elimination of corn sweeteners, including HFCS from the diet appears to contribute to the weight and BMI losses. With respect to mercury levels, the participants in the CSE group that eliminated corn sweeteners from their diet, had lower inorganic blood mercury than the one drop out in the CSE group who was unable to comply with the protocol. This individual had the highest post intervention mercury level of all at 5.01 $\mathrm{ng} / \mathrm{g}$.

In follow up interviews, the participants in the CSE group stated the task of eliminating HFCS and other corn sweetener from their diet was difficult. They felt HFCS was "addictive." The addictive property of fructose has been compared to that of ethanol [60]. Although the restrictive diet was stressful, the participants in the CSE group felt their role in the study was important and wanted to succeed in their goal of eliminating HFCS and corn sweeteners from their diet. The participants stated they found the support group "helpful." The weekly sessions enabled them to monitor their dietary intake to achieve their goal of eliminating HFCS and other corn sweeteners from their diets. Previous research shows that self-monitoring and goal-setting enhances self-efficacy and fosters behavior change beyond what is seen with just knowledge alone [61]. The results of this pilot study demonstrate the added value of goal setting and self-monitoring in a support group setting to knowledge gained through macroepigenetics workshop attendance.

The MAC intervention course was a successful tool in changing the dietary behavior of the participants in the study who took the online course. The curriculum provided a pathway of learning to improve student knowledge of toxic invasive substances in the food supply. Participants engaged in healthier eating habits as a result of the instruction. They significantly reduced their consumption of highly processed foods, invasive toxic substances, including I-Hg, which may 
be associated with the development of insulin resistance and T2D. The fasting glucose levels of the participants in the MAC intervention course significantly decreased along with their dietary changes that resulted in lower blood I-Hg levels compared to the CSE group.

This study is the first to show a direct relationship between blood inorganic $\mathrm{Hg}(\mathrm{I}-\mathrm{Hg})$ and fasting blood glucose levels. The NHANES dataset analyses revealed this relationship is unique to blood $\mathrm{I}-\mathrm{Hg}$ as glucose was not associated with blood organic mercury after adjustment for age, race, and gender. Blood organic mercury $\left(\mathrm{CH}_{3} \mathrm{Hg}\right)$ was inversely associated with insulin. It has previously been argued that blood I-Hg is the best biomarker found in NHANES for the assessment of I-Hg deposition in the body and toxic effect [62]. In contrast, blood organic $\left(\mathrm{CH}_{3} \mathrm{Hg}\right)$ and urinary mercury are measures of more recent exposure. Our results indicate recent organic mercury exposure affects insulin levels but not glucose levels, whereas chronic I-Hg exposure affects blood glucose levels. Following this logic, it may be inferred that I-Hg deposition due to chronic dietary mercury exposure has a direct relationship with blood glucose levels and may be a significant factor in the development of T2D.

I-Hg mercury may pass through the intestinal barrier into the blood stream via multiple mechanisms [63] depending on intestinal permeability. Teixeira et al. [64] describe the mechanisms that influence intestinal permeability in obesity to include: gut bacteria and other microbiota, high fructose and high fat diet, and nutritional deficiencies. Ingested food may be rich in sulfur or sulfhydryl-containing molecules [63]. These molecules bind easily to I-Hg [63] and are attached to proteins that may cross the intestinal barrier when it has become permeable by a high fat or high fructose diet. One sulfhydryl-containing protein that may play a role in the transfer of I-Hg across the intestinal barrier is serum albumin [63] which is endogenous to the intestinal tract [65]. In a recent study of the metabolism of ingested mercuric compounds, Yun et al. [66] determined the I-Hg mercury containing

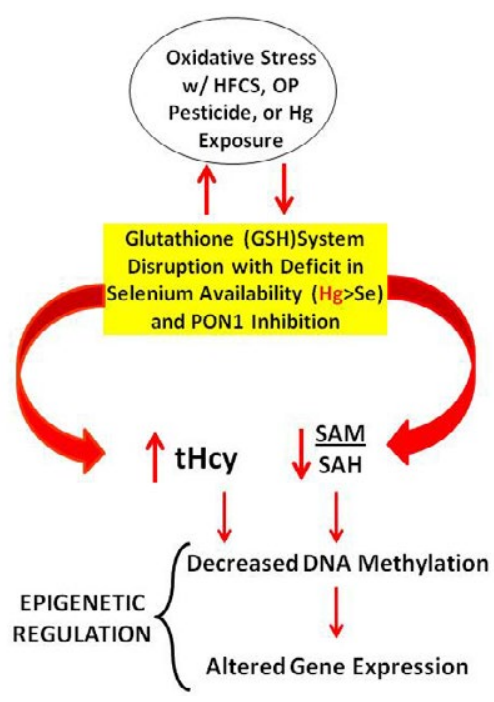

Figure 2: Dietary factors create oxidative stress and impact epigenetic regulation.

Legend: Figure 2 shows the model that explains how PON1 gene status may be impacted by dietary factors high fructose corn syrup (HFCS) and inorganic mercury (Hg). When the diet is insufficient in selenium ( $\mathrm{Se}$ ) relative to $\mathrm{Hg}$, there is disruption in the glutathione (GSH) system that creates oxidative stress. In the cycle of oxidative stress, a decrease in the S-adenosylmethionine $(S A M)$ to S-adenosylhomocysteine $(S A H)$ ratio results and this leads to decreased DNA methylation and altered gene expression. Inhibition of PON1activity undermines the body's ability to metabolize organophosphate (OP) pesticide residues commonly found in grain and grain end products. This results in additional oxidative stress which may be marked by elevated total homocysteine levels.

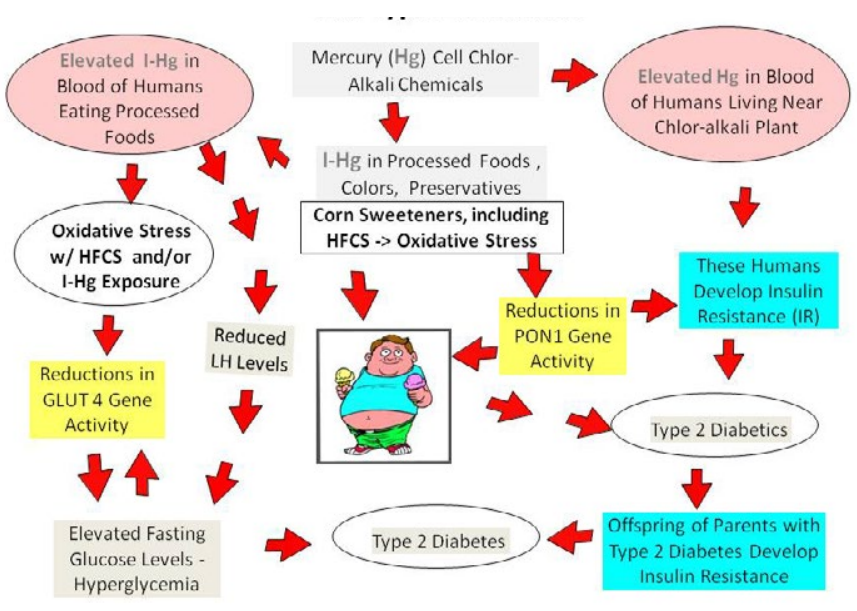

Figure 3: Macroepigenetic model of the role of $\mathrm{I}-\mathrm{Hg}$ in glucose homeostasis and type-2 diabetes.

Legend: The model is a flow chart of what can happen in the body when there is exposure to inorganic mercury ( $\mathrm{I}-\mathrm{Hg}$ ) from the environment or ingestion of foods (via corn sweeteners such as high fructose corn syrup (HFCS), food colors, chlorinated flour, or other food ingredients processed with mercury $(\mathrm{Hg})$ cell chlor-alkali chemicals). Glucose metabolism can be adversely impacted in three different ways including 1) when GLUT 4 gene expression is suppressed directly by inorganic mercury; 2) when GLUT 4 gene expression is suppressed indirectly by inorganic mercury from a reduction in luteinizing hormone ( $\mathrm{LH})$ levels and the resulting hyperglycemia; 3 ) via the oxidative stress created by inorganic mercury or HFCS exposure. Without proper GLUT 4 expression and regulation, glucose homeostasis may be disrupted resulting in elevated fasting glucose levels that could lead to the development of Type-2 Diabetes. Consumption of corn sweeteners may lead to reductions in PON1 gene expression and conditions for the development of obesity or insulin resistance leading to the eventual development of Type-2 Diabetes. Humans exposed to mercury may develop insulin resistance and Type-2 Diabetes. Offspring of parents with Type-2 Diabetics may suffer a transgenerational effect when they develop insulin resistance.

protein in human plasma is serum albumin. Once I-Hg is present in plasma, a component of blood, it may be taken up by the liver, kidney, and other organs [63]. Intestinal permeability should decrease with restricted high fructose and high fat dietary intake resulting in lower blood I-Hg levels.

Another possible mechanism for the intestinal absorption of $\mathrm{I}-\mathrm{Hg}$ is dietary sodium intake from the consumption of highly processed foods. Evidence has shown that sodium ion concentration may increase I-Hg absorption from the gut [67]. As decreasing intake of processed foods should decrease sodium concentration, this may partially explain the lower blood mercury observed in the MAC group compared to the CSE group in this intervention study. Sodium intake from processed food consumption not only impacts intestinal permeability but also may decrease PON1 gene activity [68]. Dornas et al. [68] reported finding decreased PON1 activity in fructose-fed insulin resistant rats on a high-salt diet.

PON1 gene status may play a role in obesity [69] independent of genetic ancestry [70] and lead to insulin resistance and diabetes [71]. Had this study included measures for PON1 gene expression, it likely would have found increased activity with the elimination of corn sweeteners, including HFCS, and $\mathrm{I}-\mathrm{Hg}$ from the diet. PON1 gene activity can be modulated by fructose consumption $[33,22]$ and exposure to $\mathrm{I}-\mathrm{Hg}$ [72]. I- Hg may interact with cysteine residues on PON1 preventing its activation in the liver and impairing the body's ability to protect itself against oxidative stressors such as organophosphate $(\mathrm{OP})$ pesticides 
[72]. PON1 is responsible for detoxifying homocysteine thiolactone [73] and essential for reducing total homocysteine (tHcy) levels which are thought to be harmful to health [17]. Total homocysteine (tHcy) levels are elevated in patients with T2D [74] and indicative if oxidative stress resulting from a reduction in PON1 activity. Ayotte et al. [7] found a significant inverse correlation between PON1 activity and total $\mathrm{Hg}$ levels and a direct correlation between PON1 activity and selenium (Se) levels in a study focused on the Inuit population. Sufficient dietary Se intake can offset the negative impacts of $\mathrm{Hg}$ exposure [7] with increased production of glutathione $(\mathrm{GSH})$ peroxidase [75]. With deficits in dietary Se, the reverse is true. Chen et al. [76] found mercury exposure can affect the bioavailability and retention of selenium and interfere with the metabolic processes dependent on $\mathrm{Se}$ such as the GSH System. The model depicted in Figure 2 shows how epigenetic regulation may be impacted by these dietary factors and biochemical interactions. In the cycle of oxidative stress, a decrease in the S-adenosylmethionine (SAM) to S-adenosylhomocysteine (SAH) ratio results and this leads to decreased DNA methylation and altered gene expression [17].

DNA methylation also plays a key role in the regulation of genes involved in glucose homeostasis [77]. It is not known, however, if DNA methylation is implicated in the down regulation of the GLUT4 gene [77]. GLUT4 plays a major role in regulating whole body glucose homeostasis $[78,79]$ and its expression has been found to be inversely associated with insulin resistance in obese diabetics [80]. I-Hg has been found to significantly reduce GLUT 4 gene activity altering glucose metabolism in adipocytes or fat cells [38]. Mercury exposure causes a modest increase in glucose transport and may contribute to the development of insulin resistance [39] by elevating glucose levels compared to insulin. In this study, the fasting glucose levels of the participants in the MAC intervention course significantly decreased along with their dietary changes that resulted in lower blood $\mathrm{Hg}$ levels compared to the CSE group. Had this study been able to monitor GLUT4 gene expression, it likely would have found an increase in GLUT4 activity with the dietary changes that were made by the participants in the MAC intervention group. The model presented in Figure 3 shows how GLUT4 gene expression can essentially be modulated by dietary conditions of inorganic mercury (I-Hg) exposure and/or reductions in the levels of luteinizing hormone (LH) [81].

The role of mercury in affecting LH levels has been studied by researchers. Previous reports have linked chronic I-Hg exposure with reduced levels of LH in both epidemiologic studies of the US population [45] and in toxicological studies of animals [82, 83]. LH is among the known regulators of insulin release in pancreatic cells [84]. In Figure 3, we show I-Hg exposure leading to reductions in LH creating conditions for the development of hyperglycemia which can further suppress GLUT4 gene activity [81]. Recent findings by Costanzo et al. [85] confirmed glucose levels negatively correlated with $\mathrm{LH}$ leading to hyperglycemia in men with T2D. As fasting glucose levels become elevated a negative feedback loop ensues contributing to further reductions in GLUT4 gene activity.

Figure 3 shows the model of the gene-environment interactions described in this discussion from a macroepigenetic point of view and illustrates the role of $\mathrm{I}-\mathrm{Hg}$ exposure in glucose homeostasis, insulin resistance, and type-2 diabetes. It is important to note that Metformin is prescribed to patients with diabetes to control their glucose levels because of its ability to regulate GLUT4 activity $[81,86]$. Healthy dietary changes that reduce the intake of $\mathrm{I}-\mathrm{Hg}$, however, may have the same therapeutic affect on GLUT4 thereby reducing fasting glucose levels and the risk of T2D.

Mercury exposure has previously been identified as a factor in the development of T2D. He et al. [87] reported high mercury exposure in young adulthood likely contributed to elevated risk of diabetes later in life. The researchers followed 3,875 American healthy young adults, aged 20-32 years, for several years to determine what factors led to increased risk of diabetes. Two hundred eighty eight cases of diabetes were identified over 18 years of follow up [87]. The study [87] used multivariate analysis to adjust for age, sex, ethnicity, study center, education, smoking status, alcohol consumption, physical activity, family history of diabetes, dietary intake of long-chain n-3 fatty acids and $\mathrm{Mg}$, and toenail $\mathrm{Hg}$ and Se. Baseline toenail $\mathrm{Hg}$ levels were measured using neutron-activation analysis and higher mercury exposures were associated with the development of diabetes later in life [87]. In a different study, researchers investigated 1,449 non-diabetic residents living near an abandoned mercury cell chlor-alkali plant and found residents with higher blood $\mathrm{Hg}$ or serum dioxins were at significantly higher risk for insulin resistance [40]. Abandoned mercury cell chloralkali plants release mercury into the air, soil, and water polluting the local environment for many years because treatment technologies are not yet available to clean up these facilities [88]. Mercury exposures in the residents living near the mercury cell chlor-alkali plant likely occurred through the consumption of contaminated fish caught locally, consumption of contaminated crops grown locally, inhalation of contaminated air, and ingestion of contaminated water [89]. Figure 3 shows these relationships.

Although fish and seafood consumption is thought to be the primary source of dietary mercury exposure, the results of the present study and recent evidence suggests this may not always be the case. From data derived from a food frequency questionnaire and blood samples collected from 4,484 pregnant women for mercury analysis, Golding et al. [90] estimated the contributions of 103 dietary variables to whole blood total mercury levels in the United Kingdom (UK). Although seafood was identified as a source of dietary mercury, it was determined to be a small proportion of the variation in the total blood mercury [90]. Maternal diet only accounted for $19.8 \%$ of the total variation in total blood mercury levels [90]. Forty four percent of the dietassociated variability was attributed to seafood consumption with the remaining diet-associated variability accounted for by wine and herbal teas, sunflower oil, bread, fresh fruit, and health food [90]. Golding et al. [90] did not consider HFCS as a source of mercury exposure in their study probably because it is not a significant food ingredient used in the UK due to trade restrictions. The results of the present study suggest that low level mercury exposure in the AI population living in the Fort Peck, Montana community occurs primarily through the consumption of highly processed foods including corn sweeteners.

The problem of heavy metal exposure from the consumption of food was emphasized recently in a study published by Kahn et al. [13]. Kahn et al. reported the concentrations of $\mathrm{Cr}, \mathrm{Cu}, \mathrm{Mn}, \mathrm{Ni}, \mathrm{Pb}$, and $\mathrm{Zn}$ in food significantly correlated with the concentrations of the same metals found in the blood samples of the human subjects who consumed the food [13]. Higher dietary intake of heavy metals results in higher concentrations of heavy metals in blood and the associated changes in metabolism. For example, elevated serum concentrations of $\mathrm{Pb}$ and $\mathrm{Hg}$ were recently correlated with changes in diastolic blood pressure, fasting blood glucose, total cholesterol, triglycerides, and alanine aminotransaminase [91]. Other studies have also found associations between metals exposure and cardiometabolic risk [92], 
particularly with $\mathrm{Hg}$ exposure [93]. He et al. [87] reported higher organic $\mathrm{Hg}$ exposure at baseline was also significantly associated with decreased HOMA-B in the 3,875 American healthy young adults that were followed for many years to determine what factors lead to increased risk of diabetes. The results of the present study suggest I-Hg exposure may have a greater impact on HOMA-IR.

In the present study, average HOMA-IR values declined between the pre and post period in both intervention groups. HOMA-IR is calculated using a formula employing fasting insulin and glucose concentrations in plasma [94]. If insulin values remain constant, HOMA-IR increases in response to a rise in glucose levels. The findings of this study suggest that as I-Hg and fasting glucose levels increase so will HOMA-IR values. Chang et al. [40], in fact, found that HOMA-IR values increased for individuals with higher total blood mercury levels. The downward trend in the average HOMA-IR values in this study is a positive outcome for the AI participants, especially in the MAC intervention group with the pre test HOMA-IR value of 4.14 declining to the post test HOMA-IR value of 2.98. Zhang et al. [95] reported the risk of a cardiovascular disease event increased significantly in a nondiabetic AI population when HOMA-IR values $\geq 3.57$. Interventions aimed at reducing blood mercury levels in the AI population should therefore reduce risk of cardiovascular disease.

This study did not attempt to determine the mercury exposure in the participants associated with dental amalgam. Elemental mercury exposure from dental amalgam is best determined by measuring urinary mercury levels [96]. Urine samples were not collected for mercury analysis as part of this study design. Fortunately, none of the participants in the study reported having undergone any dental procedures during the 10 -week intervention period.

There is evidence to suggest the metabolic condition of insulin resistance may be passed on from diabetic parents to their offspring $[97,98]$. Figure 3 shows this transgenerational effect. In analyzing biomarker data collected by the US National Health and Nutrition Examination Survey (NHANES) from 6,174 women of childbearing age, Laks [45] found an upward trend in the blood inorganic Hg (I$\mathrm{Hg}$ ) levels. Within the population under study, detection of I-Hg levels rose sharply from $2 \%$ of the women in $1999-2000$ to $30 \%$ in 2005 2006. It is therefore essential that a precautionary approach be taken and appropriate health education interventions focusing on dietary change be implemented to combat the obesity and T2D epidemics in the AI population. This study and successful alternative intervention approach is an example of the precautionary principle in action. The precautionary principle states "When an activity raises threats of harm to human health or the environment, precautionary measures should be taken even if some cause and effect relationships are not fully established scientifically [99]." Clearly the higher HFCS and processed food availability combined with preliminary studies raise a threat of harm to high HFCS and processed food consumers and intervention is appropriate. Recent understanding of the epigenetic changes induced by invasive toxic substances in the food supply indicates that dietary changes are appropriate.

Future intervention studies should include a significantly larger sample size. The findings of this small Phase I pilot study show there is a large effect and the intervention is ready for Phase II with more subjects and a control group. The future Phase II study should focus on changes in gene activity associated with the elimination of corn sweeteners, including HFCS, and highly processed foods from the diet. A better understanding of gene-environment interactions related to glucose homeostasis and the development of insulin resistance would likely be achieved and lead to continued improvements in health education programs designed to reduce risk factors for T2D.

\section{Conclusions}

Community based participatory research aimed at testing dietary interventions to improve health outcomes can lead to significant findings even with small sample sizes when the findings can be validated by accessing public databases and analyzing variables of interest in larger datasets such as those found in NHANES. In this study, reductions in the consumption of processed foods led to the finding of a direct relationship between inorganic blood mercury and glucose in the human population. The design and content of the macroepigenetics nutrition intervention course played a role in helping the participants make diet behavior changes leading to significant reductions in fasting glucose and lower blood mercury levels compared to the participants who eliminated corn sweeteners, including HFCS from their diet. The CSE support group played a role in helping the participants make diet behavior changes leading to significant reductions in body weight and BMI. These changes in diet behavior, fasting glucose, weight and BMI likely reduced the participants' risk of developing T2D.

The need to educate nutrition and health education professionals in this area is essential. Since dietitians, nutritionists, and health educators are the source of nutrition information for the public, they must have an understanding of this emerging field of macroepigenetics and, in particular, the macroepigenetic model for the role of I-Hg exposure in glucose homeostasis and T2D illustrated in Figure 3. Our findings suggest that chronic inorganic mercury exposure may adversely impact glucose homeostasis via different mechanisms thereby increasing the risk of T2D.

\section{List of abbreviations}

NHANES: National Health and Nutrition Examination Survey, BMI: body mass index, AI: American Indian, AN: Alaska Native, USA: United States of America, T2D: type-2 diabetes, Cr: chromium, $\mathrm{Cu}$ : copper, $\mathrm{Mn}$ : manganese, $\mathrm{Ni}$ : nickel, $\mathrm{Pb}$ : lead, $\mathrm{Zn}$ : zinc, $\mathrm{Mg}$ : magnesium, P: phosphorus, HFCS: high fructose corn syrup, PON1: paraoxonase gene, FPCC: Fort Peck Community College, $\mathrm{HgCl}_{2}$ : mercuric chloride, I-Hg: inorganic mercury, LOD: limit of detection, MAC: macroepigenetics nutrition intervention course, CSE: corn sweetener elimination support group intervention, IRB: institutional review board, FIHRI: Food Ingredient and Health Research Institute, NEMHS: Northeast Montana Health Services, USDA: United States Department of Agriculture, HOMA-IR: homeostasis model of assessment for insulin resistance, Hg: mercury, CDC: Centers for Disease Control, EPA: Environmental Protection Agency, D-IDMS: direct isotope dilution mass spectrometry, ICP-MS: inductively coupled plasma mass spectrometry, $\mathrm{CH}_{3} \mathrm{Hg}$ : methylmercury, SIDMS: speciated isotope dilution mass spectrometry, GC: gas chromatograph, RCRA: Resource Conservation and Recovery Act, SD: standard deviation, OP: organophosphate pesticide, tHCY: total homocysteine, Se: selenium, GSH: glutathione, SAM: S-adenosylmethionine , SAH: S-adenosylhomocysteine, GLUT4: gene involved in glucose homeostasis, LH: luteinizing hormone, UK: United Kingdom

\section{Authors' contributions}

R. Dufault spearheaded the design of the project and recruited interdisciplinary collaborators to contribute to the development of the manuscript. R. Dufault was the Principal Investigator and 
worked collaboratively with stakeholders to develop the curriculum for the online macroepigenetics nutrition intervention course. $\mathrm{R}$. Dufault delivered the on line instruction for the intervention course and developed the epigenetic model to explain the role of mercury in glucose homeostasis and T2D. R. Dufault prepared Figures 2 and 3 and tables 1, 2, 4, 5, and 6. R. Dufault recruited the collaborators to perform the tasks needed to refine and support the model (Figure 3). Z. Berg served as the on-site Co-Investigator at FPCC and managed a variety of tasks associated with the success of this project to include recruiting and providing compensation for community members to participate in the study. Z. Berg also managed the support group. R. Crider analyzed and validated the data sets in Tables 1, 2, 3, 4, 5, and 6 to ensure accuracy. R. Schnoll provided consultation on some of the nutritional content of the course and validated all of the references. L. Wetsit and W. Two Bulls reviewed the manuscript and added the community perspective. S. Gilbert added the intellectual content from the precautionary principle point of view and edited the manuscript. H.M."Skip" Kingston, Mesay M. Wolle, and M. Rahman performed the mercury speciated analyses and developed the EPA methods used in analyses. D. Laks performed the statistical analyses of the NHANES dataset to determine the direct relationship between blood I-Hg and fasting blood glucose. D. Laks prepared Figures 1 and Table 3 and helped refine Figure 3. All authors read and approved the final manuscript.

\section{Lead author's information}

R. Dufault retired early with honors from her position as a Public Health Service officer at the U.S. Food and Drug Administration (FDA) in 2008 to continue her investigation of mercury in high fructose corn syrup. For a few years, she taught elementary special education during the day while continuing her research at night and on weekends. In also teaching a popular online course at the United Tribes Technical College, over several years, she developed relationships with many American Indians in communities across the U.S. It is through these relationships that this study came about. R. Dufault now serves as the volunteer Founding Director of the Food Ingredient and Health Research Institute.

\section{Acknowledgement}

The authors would like to thank the Food Ingredient and Health Research Institute, American Indian Higher Education Consortium and the U.S. Environmental Protection Agency (EPA) for providing the funding for this project through Award No.: EP-11-H-000737 and EP-W-12-023. We would like to acknowledge the in kind contributions of the nursing staff, Abby Reum and Lauri Handy, at the Northeast Montana Health Services Riverside Clinic who screened and selected the community members for participation in this study. We would also like to express our gratitude to the community members at Fort Peck Community College in Montana who participated in this study for without them this project would not have been possible.

\section{References}

1. Barnes PM, Adams PF, Powell-Griner E (2010) Health characteristics of the American Indian or Alaska Native adult population: United States, 2004-2008. National Health Statistics Reports 20: 1-22.

2. Anderson RN, Smith BL (2003) Deaths: leading causes for 2001. National Vital Statistics Reports : from the Centers for Disease Control and Prevention, National Center for Health Statistics, National Vital Statistics System. 52: 1-85.

3. Jobe JB, Adams AK, Henderson JA, Karanja N, Lee ET, et al. (2012) Communityresponsive interventions to reduce cardiovascular risk in American Indians. J Prim Prev 33: 153-9. [Crossref]
4. Centers for Disease Control and Prevention (2003) Diabetes prevalence among American Indians and Alaska Natives and the overall population -- United States, 19942002. MMWR 52: 702-4. [Crossref]

5. Centers for Disease Control and Prevention: National diabetes statistics report (2014)

6. Schell LM, Gallo MV (2012) Overweight and obesity among North American Indian infants, children, and youth. Am J Hum Biol 24: 302-313. [Crossref]

7. Ayotte P, Carrier A, Ouellet N, Boiteau V, Abdous B, et al. (2011) Relation between methylmercury exposure and plasma paraoxonase activity in inuit adults from Nunavik. Environ Health Perspect 119: 1077-1083.[Crossref]

8. Chen YW, Yang CY, Huang CF, Hung DZ, Leung YM, et al. (2009) Heavy metals, islet function and diabetes development. Islets 1:169-76. [Crossref]

9. Codru N, Schymura MJ, Negoita S, Akwesasne Task Force on Environment, Rej R, et al. (2007) Diabetes in relation to serum levels of polychlorinated biphenyls and chlorinated pesticides in adult Native Americans. Environ Health Perspect 115: 1442 7. [Crossref]

10. Thayer KA, Heindel JJ, Bucher JR, Gallo MA (2012) Role of environmental chemicals in diabetes and obesity: a National Toxicology Program workshop review. Environ Health Perspect 120: 779-89. [Crossref]

11. Stanhope KL, Schwarz JM, Havel PJ (2013) Adverse metabolic effects of dietary fructose: results from the recent epidemiological, clinical, and mechanistic studies. Curr Opin Lipidol 24: 198-206.

12. Shenkin A (2006) The key role of micronutrients. Clinical Nutrition 25: 1-13.

13. Khan K, Khan H, Lu Y, Ihsanullah I, Nawab J, et al. (2014) Evaluation of toxicological risk of foodstuffs contaminated with heavy metals in Swat, Pakistan. Ecotoxicol Environ Saf 108: 224-32. [Crossref]

14. Fialkowski MK, McCrory MA, Roberts SM, Tracy JK, Grattan LM, et al. (2010) Estimated nutrient intakes from food generally do not meet dietary reference intakes among adult members of Pacific Northwest tribal nations. J Nutr 140: 992-8. [Crossref]

15. Moshfegh A, Goldman J, Ahuja J, Rhodes D, LaComb R (2009) What we eat in America, NHANES 2005-2006: usual nutrient intakes from food and water compared to 1997 dietary reference intakes for vitamin D, calcium, phosphorus, and magnesium. U.S. Department of Agriculture, Agricultureal Research Service.

16. Del Gobbo LC, Song Y, Elin RJ, Meltzer SJ, Egeland GM (2012) Gestational glucose intolerance modifies the association between magnesium and glycemic variables in mothers and daughters 15 years post-partum. Magnesium $25: 54-63$. [Crossref]

17. Dufault R, Lukiw WJ, Crider R, Schnoll R, Wallinga D, et al. (2012) A macroepigenetic approach to identify factors responsible for the autism epidemic in the United States. Clin Epigenetics 4: 6. [Crossref]

18. McKeag NA, McKinley MC, Woodside JV, Harbinson MT, McKeown PP (2012) The role of micronutrients in heart failure. J Acad Nutr Diet 112: 870-886. [Crossref]

19. Rosanoff A, Weaver CM, Rude RK (2012) Suboptimal magnesium status in the United States: are the health consequences underestimated? Nutrition Reviews 70: 153-64.

20. Ivaturi R, Kies C (1992) Mineral balances in humans as affected by fructose, high fructose corn syrup and sucrose. Plant Foods Hum Nutr 42: 143-151. [Crossref]

21. Milne DB, Nielsen FH (2000) The interaction between dietary fructose and magnesium adversely affects macromineral homeostasis in men. J Am Coll Nutr 19: 31-37. [Crossref]

22. Costa LG, Giordano G, Furlong CE (2011) Pharmacological and dietary modulators of paraoxonase 1 (PON1) activity and expression: the hunt goes on. Biochem Pharmacol 81: 337-344. [Crossref]

23. Rayssiguier Y, Gueux E, Nowacki W, Rock E, Mazur A (2006) High fructose consumption combined with low dietary magnesium intake may increase the incidence of the metabolic syndrome by inducing inflammation. Magnesium Research : official organ of the International Society for the Development of Research on Magnesium 19: $237-43$.

24. Hoover E, Cook K, Plain R, Sanchez K, Waghiyi V, et al. (2012) Indigenous peoples of North America: environmental exposures and reproductive justice. Environ Health Perspec 120: 1645-9.

25. Cadzow RB, Craig M, Rowe J, Kahn LS (2013) Transforming community members into diabetes cultural health brokers: the Neighborhood Health Talker project. Diabetes Educ 39: 100-108. [Crossref]

26. US Environmental Protection Agency (EPA):Tribal ecoambassadors 2011-2012 
Dufault R (2015) Blood inorganic mercury is directly associated with glucose levels in the human population and may be linked to processed food intake

program: EPA and tribal colleges and universities work together to solve environmental problems in tribal communities.

27. Zeisel SH (2013) Metabolic crosstalk between choline/1-carbon metabolism and energy homeostasis. Clinical Chemistry and Laboratory Medicine: CCLM / FESCC 51: $467-75$.

28. Klassen CD (2013) Casarett \& Doull's Toxicology: The Basic Science of Poisons (8th Edition). New York: McGraw Hill Education.

29. Hamlin JC, Pauly M, Melnyk S, Pavliv O, Starrett W, et al. (2013) Dietary intake and plasma levels of choline and betaine in children with autism spectrum disorders. Autism Res Treat 2013: 578429.[Crossref]

30. Guzmán-Maldonado H, Paredes-López O (1995) Amylolytic enzymes and products derived from starch: a review. Crit Rev Food Sci Nutr 35: 373-403. [Crossref]

31. Dufault R, LeBlanc B, Schnoll R, Cornett C, Schweitzer L, et al. (2009) Mercury from chlor-alkali plants: measured concentrations in food product sugar. Environmental Health: a global access science source $8: 2$.

32. Rideout K (2010) Comment on the paper by Dufault et al.: mercury in foods containing high-fructose corn syrup in Canada. Environmental Health: a global access science source.

33. Ackerman Z, Oron-Herman M, Pappo O, Peleg E, Safadi R, et al. (2010) Hepatic effects of rosiglitazone in rats with the metabolic syndrome. Basic Clin Pharmacol Toxicol 107: 663-668. [Crossref]

34. Pooranaperundevi M, Sumiyabanu MS, Viswanathan P, Sundarapandiyan R, Anuradha CV (2010) Insulin resistance induced by a high-fructose diet potentiates thioacetamide hepatotoxicity. Singapore Med J 51: 389-98. [Crossref]

35. Schultz A, Neil D, Aguila MB, Mandarim-de-Lacerda CA (2013) Hepatic adverse effects of fructose consumption independent of overweight/obesity. Int J Mol Sci 14: 21873-86. [Crossref]

36. US Department of Agriculture: PDP - databases and annual summaries (2004).

37. Yamada A, Shoji T, Tahara H, Emoto M, Nishizawa Y (2001) Effect of insulin resistance on serum paraoxonase activity in a nondiabetic population. Metabolism 50: 805-811. [Crossref]

38. Barnes DM, Hanlon PR, Kircher EA (2003) Effects of inorganic $\mathrm{HgCl} 2$ on adipogenesis. Toxicol Sci 75: 368-377. [Crossref]

39. Barnes DM, Kircher EA (2005) Effects of mercuric chloride on glucose transport in 3T3-L1 adipocytes. Toxicol In Vitro 19: 207-214. [Crossref]

40. Chang JW, Chen HL, Su HJ, Liao PC, Guo HR, et al. (2011) Simultaneous exposure of non-diabetics to high levels of dioxins and mercury increases their risk of insulin resistance. J Hazard Mater 185: 749-755.[Crossref]

41. US Environmental Protection Agency (EPA): Inorganic mercury (2007).

42. European Feed Ingredients Safety Certification: Sector reference document on the manufacturing of safe feed materials from oilseed crushing and vegetable oil refining.

43. Food and Agriculture Organization of the United Nations (FAO): Chorine monograph.

44. Dufault RJ: Food and medicine (videotape), health and culture symposium (2014) Smithsonian Institute National Museum of the American Indian.

45. Laks DR (2009) Assessment of chronic mercury exposure within the U.S. population, National Health and Nutrition Examination Survey, 1999-2006. Biometals 22: 1103-14. [Crossref]

46. BioMed IRB: Today's only non-profit IRB.

47. Food Ingredient and Health Research Institute (FIHRI) (2013) Applied macroepigenetics course.

48. US Department of Agriculture (USDA) (2014) Food availability (per capita) data system.

49. Survey Monkey: Create surveys, get answers.

50. National Cancer Institute (NCI): Diet history questionnaire II.

51. Gastroenterology and Hepatology Resources: HOMA-IR calculator.

52. Rahman GMM, Wolle MM, Fahrenholz T, Kingston HM (2014) "Skip", Pamuku M. Measurement of mercury species in whole blood using speciated isotope dilution methodology integrated with microwave-enhanced solubilization and spike equilibrium, headspace - solid - phase microextraction, and GC-ICP-MS analysis. Analy Chem 86: 6130-6137.
53. US Environmental Protection Agency. Resource conservation and recovery act test methods, sw-846 on-line.

54. Simple Interactive Statistical Analysis: T-test.

55. Goran M, Ulijaszek SJ, Ventura EE (2013) High fructose corn syrup and diabetes prevalence: a global perspective. Glob Public Health 8: 55-64. [Crossref]

56. Esparza-Romero J, Valencia ME, Martinez ME, Ravussin E, Schulz LO, et al. (2010) Differences in insulin resistance in Mexican and U.S. Pima Indians with normal glucose tolerance. J Clin Endocrinol Metab 95: E358-362. [Crossref]

57. Harmon K (2012) Global high fructose corn syrup use may be fueling diabetes increase. Scientific American.

58. Bray GA, Nielsen SJ, Popkin BM (2004) Consumption of high-fructose corn syrup in beverages may play a role in the epidemic of obesity. Am J Clin Nutr 79: 537-543. [Crossref]

59. Stanhope KL, Schwarz JM, Keim NL, Griffen SC, Bremer AA, et al. (2009) Consuming fructose-sweetened, not glucose-sweetened, beverages increases visceral adiposity and lipids and decreases insulin sensitivity in overweight/obese humans. J Clin Invest 119 : 1322-34. [Crossref]

60. Lustig RH (2010) Fructose: metabolic, hedonic, and societal parallels with ethanol. $J$ Am Diet Assoc 110: 1307-1321. [Crossref]

61. Schnoll R, Zimmerman BJ (2001) Self-regulation training enhances dietary selfefficacy and dietary fiber consumption. J Am Diet Assoc 101: 1006-1011. [Crossref]

62. Laks DR (2014) Mercury rising: response to the EPA assessment of mercury exposure. Biometals 27: 1-4. [Crossref]

63. Bridges CC, Zalups RK (2010) Transport of inorganic mercury and methylmercury in target tissues and organs. J Toxicol Environ Health B Crit Rev 13: 385-410. [Crossref]

64. Teixeira TF, Collado MC, Ferreira CL, Bressan J, Peluzio Mdo C (2012) Potential mechanisms for the emerging link between obesity and increased intestinal permeability. Nutrition Res 32: 637-47.

65. Moughan PJ, Rutherfurd SM, Montoya CA, Dave LA (2014) Food-derived bioactive peptides--a new paradigm. Nutr Res Rev 27: 16-20. [Crossref]

66. Yun Z, Li L, Liu L, He B, Zhao X, et al. (2013) Characterization of mercury-containing protein in human plasma. Metallomics 5: 821-827. [Crossref]

67. Endo T, Nakaya S, Kimura R (1988) Mechanisms of absorption of inorganic mercury from rat small intestine. I. Solvent drag effect on absorption of inorganic mercury. Pharmacol Toxicol 63: 8-15. [Crossref]

68. Dornas WC, de Lima WG, Dos Santos RC, de Souza MO, Silva M, et al. (2012) Salt overload in fructose-fed insulin-resistant rats decreases paraoxonase-1 activity. Nutr Metab (Lond) 9: 63. [Crossref]

69. Seres I, Bajnok L, Harangi M, Sztanek F, Koncsos P, et al. (2010) Alteration of PON1 activity in adult and childhood obesity and its relation to adipokine levels. Adv Exp Med Biol 660: 129-142. [Crossref]

70. Huen K, Harley K, Beckman K, Eskenazi B, Holland N (2013) Associations of PON and genetic ancestry with obesity in early childhood. PLoS One 8: e62565. [Crossref]

71. Ferre N, Feliu A, Garcia-Heredia A, Marsillach J, Paris N, et al. (2013) Impaired paraoxonase-1 status in obese children. Relationships with insulin resistance and metabolic syndrome. Clinical Biochemistry 46:1830-6.

72. Costa LG, Vitalone A, Cole TB, Furlong CE (2005) Modulation of paraoxonase (PON1) activity. Biochem Pharmacol 69: 541-550. [Crossref]

73. Jakubowski H (2010) The role of paraoxonase 1 in the detoxification of homocysteine thiolactone. Adv Exp Med Biol 660: 113-127. [Crossref]

74. Sudchada P, Saokaew S, Sridetch S, Incampa S, Jaiyen S, et al. (2012) Effect of folic acid supplementation on plasma total homocysteine levels and glycemic control in patients with type 2 diabetes: a systematic review and meta-analysis. Diabetes Res Clin Pract 98:151-8. [Crossref]

75. Dufault R, Schnoll R, Lukiw WJ, Leblanc B, Cornett C, et al. (2009) Mercury exposure, nutritional deficiencies and metabolic disruptions may affect learning in children. Behav Brain Funct 5: 44. [Crossref]

76. Chen C, Yu H, Zhao J, Li B, Qu L, et al. (2006) The roles of serum selenium an selenoproteins on mercury toxicity in environmental and occupational exposure. Environ Health Perspect 114: 297-301. [Crossref] 
77. Barres R, Zierath JR (2011) DNA methylation in metabolic disorders. Am J Clin Nutr 93: 897S-900. [Crossref]

78. Huang S, Czech MP (2007) The GLUT4 glucose transporter. Cell Metab 5: 237-252. [Crossref]

79. Karnieli E, Armoni M (2008) Transcriptional regulation of the insulin-responsive glucose transporter GLUT4 gene: from physiology to pathology. Am $J$ Physiol Endocrinol Metab 295: E38-45. [Crossref]

80. Kouidhi S, Berrhouma R, Rouissi K, Jarboui S, Clerget-Froidevaux MS, et al. (2013) Human subcutaneous adipose tissue Glut 4 mRNA expression in obesity and type 2 diabetes. Acta Diabetol 50: 227-232. [Crossref]

81. Zhai J, Liu CX, Tian ZR, Jiang QH, Sun YP (2012) Effects of metformin on the expression of GLUT4 in endometrium of obese women with polycystic ovary syndrome. Biol Reprod 87: 29. [Crossref]

82. Tartu S, Bustamante P, Goutte A, Cherel Y, Weimerskirch H, et al. (2014) Age-related mercury contamination and relationship with luteinizing hormone in a long-lived Antarctic bird. PLoS One 9: e103642. [Crossref]

83. Tartu S, Goutte A, Bustamante P, Angelier F, Moe B, et al. (2013) To breed or not to breed: endocrine response to mercury contamination by an Arctic seabird. Biol Lett 9 : 20130317. [Crossref]

84. Parkash J, Lei Z2, Rao CV3 (2015) The Presence of Human Chorionic Gonadotropin/ Luteinizing Hormone Receptors in Pancreatic $\hat{\mathrm{I}}^{2}$-Cells. Reprod Sci. [Crossref]

85. Costanzo PR, Suárez SM, Scaglia HE, Zylbersztein C, Litwak LE, et al. (2014) Evaluation of the hypothalamic-pituitary-gonadal axis in eugonadal men with type 2 diabetes mellitus. Andrology 2: 117-124. [Crossref]

86. Detaille D, Wiernsperger N, Devos P (1999) Metformin interaction with insulinregulated glucose uptake, using the Xenopus laevis oocyte model expressing the mammalian transporter GLUT4. Eur J Pharmacol 377:127-136. [Crossref]

87. He K, Xun P, Liu K, Morris S, Reis J, et al. (2013) Mercury exposure in young adulthood and incidence of diabetes later in life: the CARDIA Trace Element Study. Diabetes Care 36: 1584-1589. [Crossref]

88. US Environmental Protection Agency (2007) Treatment technologies for mercury in soil, waste, and water.
89. Huang SW, Chen CY, Chen MH (2008) Total and organic hg in fish from the reservoir of a chlor-alkali plant in Tainan, Taiwan. J Food and Drug Analysis 16: 75-80.

90. Golding J, Steer CD, Hibbeln JR, Emmett PM, Lowery T, et al. (2013) Dietary predictors of maternal prenatal blood mercury levels in the ALSPAC birth cohort study. Environ Health Perspect 121: 1214-8. [Crossref]

91. Poursafa P, Ataee E, Motlagh ME, Ardalan G, Tajadini MH, et al. (2014) Association of serum lead and mercury level with cardiometabolic risk factors and liver enzymes in a nationally representative sample of adolescents: the CASPIAN-III study. Environl Sci Pollut Res Int 21: 13496-502. [Crossref]

92. Ettinger AS, Bovet P, Plange-Rhule J, Forrester TE, Lambert EV, et al. (2014) Distribution of metals exposure and associations with cardiometabolic risk factors in the "Modeling the Epidemiologic Transition Study". Environ Health 13: 90. [Crossref]

93. Eom SY, Choi SH, Ahn SJ, Kim DK, et al. (2014) Reference levels of blood mercury and association with metabolic syndrome in Korean adults. Int Arch Occup Environ Health 87: 501-513. [Crossref]

94. Abbasi F, Okeke Q, Reaven GM (2014) Evaluation of fasting plasma insulin concentration as an estimate of insulin action in nondiabetic individuals: comparison with the homeostasis model assessment of insulin resistance (HOMA-IR). Acto Diabetologica 51:193-7. [Crossref]

95. Zhang Y, Lee ET, Howard BV, Best LG, Umans JG, et al. (2013) Insulin resistance, incident cardiovascular diseases, and decreased kidney function among nondiabetic American Indians: the Strong Heart Study. Diabetes Care 36: 3195-200. [Crossref]

96. Rathore M, Singh A, Pant VA (2012) The dental amalgam toxicity fear: a myth or actuality. Toxicol Int 19: 81-88. [Crossref]

97. Petersen KF, Dufour S, Shulman GI (2005) Decreased insulin-stimulated ATP synthesis and phosphate transport in muscle of insulin-resistant offspring of type 2 diabetic parents. PLoS Med 2: e233.[Crossref]

98. Warram JH, Martin BC, Krolewski AS, Soeldner JS, Kahn CR (1990) Slow glucose removal rate and hyperinsulinemia precede the development of type II diabetes in the offspring of diabetic parents. Ann Intern Med 113: 909-915. [Crossref]

99. Science and Environmental Health Network: Wingspread consensus statement on the precautionary principle (1998).

Copyright: $(2015$ Dufault R. This is an open-access article distributed under the terms of the Creative Commons Attribution License, which permits unrestricted use, distribution, and reproduction in any medium, provided the original author and source are credited. 